\title{
BMJ Open Decade of research into the acceptability of interventions aimed at improving adolescent and youth health and social outcomes in Africa: a systematic review and evidence map
}

Oluwaseyi Dolapo Somefun (D) , ${ }^{1}$ Marisa Casale, ${ }^{1,2}$ Genevieve Haupt Ronnie, ${ }^{3}$ Chris Desmond, ${ }^{4}$ Lucie Cluver, ${ }^{2,5}$ Lorraine Sherr ${ }^{6}$

To cite: Somefun OD, Casale M, Haupt Ronnie G, et al. Decade of research into the acceptability of interventions aimed at improving adolescent and youth health and social outcomes in Africa: a systematic review and evidence map. BMJ Open 2021;11:e055160. doi:10.1136/ bmjopen-2021-055160

- Prepublication history and additional supplemental material for this paper are available online. To view these files, please visit the journal online (http://dx.doi.org/10.1136/ bmjopen-2021-055160).

Received 05 July 2021 Accepted 04 November 2021

Check for updates

(C) Author(s) (or their employer(s)) 2021. Re-use permitted under CC BY-NC. No commercial re-use. See rights and permissions. Published by BMJ.

For numbered affiliations see end of article.

Correspondence to Dr Oluwaseyi Dolapo Somefun; seyi.somefun@gmail.com

\section{ABSTRACT}

Objective Interventions aimed at improving adolescent health and social outcomes are more likely to be successful if the young people they target find them acceptable. However, no standard definitions or indicators exist to assess acceptability. Acceptability research with adolescents in low-and-middle-income countries (LMICs) is still limited and no known reviews systhesise the evidence from Africa. This paper maps and qualitatively synthesises the scope, characteristics and findings of these studies, including definitions of acceptability, methods used, the type and objectives of interventions assessed, and overall findings on adolescent acceptability. Design We conducted a systematic review of peerreviewed studies assessing intervention acceptability with young adults (aged 10-24) in Africa, published between January 2010 and June 2020.

Data sources Web of Science, Medline, PsycINF0, Socilndex, CINAHL, Africa-wide, Academic Search Complete and PubMed were searched through July 2020.

Eligibility criteria for selecting studies Papers were selected based on the following inclusion criteria: if they (1) reported primary research assessing acceptability (based on the authors' definition of the study or findings) of one or more intervention(s) with adolescents and young adults 10-24; (2) assessed acceptability of intervention(s) aimed at positively influencing one or more development outcome(s), as defined by sustainable development goal (SDG) indicators; (3) reported on research conducted in Africa; (4) were in the English Language; (5) were peer-reviewed and and (6) were published between 1 January 2010 and 30 June 2020.

Data extraction and synthesis Abstracts were reviewed independently by the two first authors to determine relevance. Full text of potentially eligible studies were retrieved and independently examined by the same two authors; areas of disagreement or lack of clarity were resolved through discussion by the two authors andwhere necessary - the assessment of a third author. Results 55 studies were considered eligible for inclusion in the review. Most studies were conducted in Southern Africa, of which 32 jointly in South Africa and Uganda. The majority of interventions assessed for acceptability could be classified as HIV or HPV vaccine interventions (10), E-health (10), HIV
Strengths and limitations of this study

- This systematic review was carried out in line with the Preferred Reporting Items for Systematic Reviews and Meta-Analyses.

- Our search strategy and composite search strings were sufficiently broad in scope to include studies assessing all types of interventions aimed at improving health and other social outcomes among adolescents and youth in Africa.

- Screening of study abstracts and full text, as well as data extraction, were conducted independently by at least two authors.

- Our review did not include studies conducted before 2010.

- The review did not include a quality assessment given the diversity of study designs, though we note this is not a prerequisite for a mapping review.

testing interventions (8), support group interventions (7) and contraceptive interventions (6). The objectives of most interventions were linked to SDG3, specifically to HIV and sexual and reproductive health. Acceptability was overall high among these published studies. 22 studies provided reasons for acceptability or lack thereof, some specific to particular types of interventions and others common across intervention types.

Conclusions Our review exposes considerable scope for future acceptability research and review work. This should include extending acceptability research beyond the health (and particularly HIV) sector and to regions in Africa where this type of research is still scarce; including adolescents earlier, and potentially throughout the intervention process; further conceptualising the construct of acceptability among adolescents and beyond; and examining the relationship between acceptability and uptake.

\section{INTRODUCTION}

Addressing the developmental needs of adolescents and youth in African countries is critical if the continent is to achieve its 
Sustainable Development Goals (SDGs), and envisaged transformation articulated in the African Union's overarching Agenda 2063. ${ }^{12}$ Adolescents make up the largest generation of their age group in history, ${ }^{3}$ and sub-Saharan Africa accounts for over $20 \%$ of the estimated 1.8 billion adolescents and young adults globally. ${ }^{4}$ Investing in adolescent well-being can have positive effects for individuals during adolescence and beyond, as well as potential positive societal effects. Interventions that reduce the consequences of poverty among adolescents, or lead to more positive behaviours, can influence development and well-being during adolescence and throughout the life course ${ }^{5-7}$ Investment during adolescence can strengthen early childhood investments and reduce the burden of morbidity and mortality in adulthood. ${ }^{8}$ Moreover, it has been argued that investment in adolescents can help realise the "demographic dividend" ${ }^{910}$ and reduce generational inequalities. ${ }^{11}$

Substantial investment has been made globally in adolescent interventions. These have focused on areas such as sexual and reproductive health, nutrition, uptake of vaccines and prevention of substance abuse. ${ }^{12}$ Unfortunately, these interventions have not always recorded impressive impact. ${ }^{13}$ Data from both high-income countries (HICs) and low-income and middle-income countries (LMICs) reveal that many interventions focusing on adolescents are fragmented, poorly designed and unequal in quality. ${ }^{14}$ One reason for this may be an insufficient understanding of the particular nature of adolescence. ${ }^{15}$

Adolescence is a critical period characterised by rapid development of the physical, cognitive, social and emotional capabilities that are instrumental across their life-course. ${ }^{3}$ Adolescence is also a time of gathering independence. Pathways to learning and experiencing such independence are varied, with experiential learning playing a key role. The rapid growth associated with this phase and its influences on behaviour need to be well understood in order to design timely and effective interventions. ${ }^{16}$

Interventions may also fail to sufficiently consider the diverse environments in which adolescents live, that may shape their decisions and behaviour. ${ }^{17}$ This could lead to interveners missing important factors that, if unaddressed, will prevent the intervention from having the desired impact. Additionally, programme implementers may lack the specialised skills necessary for delivering and sustaining these interventions. ${ }^{12}$ Adult interventions may not translate directly for adolescent audiences and programme adjustments may be inadequate.

Since most interventions seek to effect adolescent behavioural change, many of the obstacles to uptake and effectiveness could be addressed by affording sufficient importance to the perspectives and participation of adolescents themselves. When adolescents feel coerced to engage in a particular behaviour or accept interventions that they don't identify with, they are more likely to resist the message of the proposed intervention, or to stop participating altogether. ${ }^{18}$ Instead, interventions that are acceptable to adolescent end-users are likely to have higher social validity, ${ }^{19}$ uptake and effectiveness. ${ }^{20} 21$

However, adolescent involvement and input in intervention design has been varied, and models of adolescent inclusion have been poorly envisaged and implemented. There is still a relatively low number of acceptability studies among adolescents in LMICs and specifically in Africa, particularly beyond the health sector. ${ }^{19}{ }^{20}$ To our knowledge, no existing reviews comprehensively map the extant body of acceptability research in Africa and aggregate the evidence emerging from these studies. Furthermore, there is no clear and standard definition of acceptability ${ }^{20}$ in Africa and beyond. This in turn raises several methodological challenges when setting out to assess acceptability, including the choice of measurement frameworks and tools..$^{20}$ It also highlights the scope for further conceptualisation of this construct, particularly in specific populations and geographical regions.

We conducted a systematic review to identify studies that conducted primary research with adolescents and young adults ${ }^{10-24}$ in Africa over the past decade (January 2010- June 2020), to assess the acceptability of interventions aimed at positively influencing their developmental outcomes. This paper maps and qualitatively synthesises the scope, characteristics and overall findings of studies identified. This includes evidence addressing the questions of whether and how the construct of acceptability is conceptualised and defined within these studies, the methods and indicators used, the type and key objectives of interventions assessed, as well as evidence on what adolescents find acceptable and why. Based on these findings, we aim to discuss implications for future adolescentfocused interventions in Africa and identify gaps for future acceptability research with this population.

\section{METHODS}

\section{Search strategy}

The systematic review was carried out in line with the Preferred Reporting Items for Systematic Reviews and Meta-Analyses (PRISMA). We used the Population, Intervention, Comparison, Outcome criteria ${ }^{22}$ to help determine eligibility criteria for inclusion develop the search strategy and composite search terms developed (see online supplemental table 1). We searched eight online databases (listed in online supplemental table 1), covering a wide range of behavioural science research, and searched the reference lists of eligible papers.

\section{Study selection and data extraction}

Papers were selected based on the following inclusion criteria: if they (1) reported primary research assessing acceptability (based on the authors' definition of the study or findings) of one or more intervention(s) with adolescents and young adults 10-24; (2) assessed acceptability of intervention(s) aimed at positively influencing one or more development outcome(s), as defined by SDG indicators; (3) reported on research conducted in 
Africa; (4) were in the English Language; (5) were peerreviewed and (6) were published between 1 January 2010 and 30 June 2020. We restricted our review to a 10-year period, taking into account the available researcher time and other available resources to conduct this review, and its relatively broad scope in terms of types of interventions and developmental outcomes included. We did not include limiters for study design or methodological tools, type of intervention or sector, or type of developmental outcome the intervention intended to influence. To be as inclusive as possible, we included studies that worked with broader samples (eg, youth and adults) but disaggregated the results and reported findings specifically for the age group of interest. ${ }^{10-24}$ We imported all references from the online databases into Endnote, where duplicates were identified and removed. Abstracts were reviewed independently by the two first authors (OS and MC) to determine relevance. Full text of potentially eligible studies were retrieved and independently examined by the same two authors; areas of disagreement or lack of clarity were resolved through discussion by the two authors and where necessary-the assessment of a third author $(\mathrm{GH})$. Reasons for exclusion of each paper not deemed eligible were recorded in an excel spread sheet. We developed a detailed extraction sheet, using Excel software, to extract key characteristics and findings of eligible papers. For reliability, the information for each paper was extracted separately by at least two of the first three authors and differences were resolved through discussion among the authors.

\section{PATIENT AND PUBLIC INVOLVEMENT}

Patients and the public were not involved in the preparation of this study.

\section{RESULTS}

\section{Eligible studies included in the review}

Figure 1 presents the PRISMA flow diagram describing the process of study selection and reasons for study exclusion. A total of 4692 titles and abstracts were screened after removing duplicates, 278 articles were subjected to a full-text review and a final 55 studies were considered eligible for inclusion in the review.

\section{Study characteristics: publication year, location and sample}

Below we present a summary of key characteristics of the 55 eligible studies included in our review. More than half of the papers were published between 2018 and 2020 with $22 \%$ of the papers published in 2019 , as shown in online supplemental figure 1.

Figure 2 provides a visual representation of the location of studies on the continent. There is a clear concentration of acceptability studies in South and East Africa, with approximately half of identified studies conducted in South Africa ${ }^{19}$ and Uganda. ${ }^{13}$ Only seven studies were from West and Central Africa and only one from North Africa.

Online supplemental table 2 provides information on study characteristics and overall findings for the entire list of eligible studies, and by each type of intervention category (as indicated below) in separate sheets. Most study samples included male and female participants, while 11 studies worked only with females and three with males only. 44 studies worked with samples that fell entirely within the specified age range, ${ }^{10-24}$ while 11 included studies worked with broader samples (eg, youth and adults) but disaggregated the results and reported findings specifically for the age group of interest. To be as inclusive as possible, we included 10 studies that did not clearly specify the exact age range of participants, but for which available information indicated that the sample would have been entirely or almost entirely within this range (eg, secondary school and university student ${ }^{23-28}$ or where sample descriptive data indicated a sample consisting almost entirely of participants 24 or younger. ${ }^{29-31}$

While our inclusion criteria focused on primary acceptability research with adolescents and young adults, it should be noted that 25 studies also collected acceptability data from other stakeholders. These include caregivers or other family members, ${ }^{32-40}$ teachers, facilitators,${ }^{2641} 42$ community leaders or gate keepers, ${ }^{2843}$ peer mentors, service providers and healthcare workers. ${ }^{44-51}$ Since the focus of this mapping review is the acceptability of young adults specifically, we do not synthesise or report on perspectives of other stakeholders.

\section{Types and objectives of interventions assessed for} acceptability

We categorised interventions assessed for acceptability both by type of intervention, based on their key components (see figure 3), and stated objectives of the interventions (see figure 4). In terms of type of intervention, interventions were classified as HIV or HPV vaccine interventions, ${ }^{10}$ E-health, ${ }^{10}$ HIV testing interventions, ${ }^{8}$ support group interventions, ${ }^{7}$ contraceptive interventions, ${ }^{6}$ voluntary medical male circumcision programmes, ${ }^{4}$ school-based sexual and reproductive health education, ${ }^{4}$ economic support programmes ${ }^{4}$ and pre-exposure prophylaxis. ${ }^{2}$ Five studies did not fit into the above intervention categories and were grouped as 'other'; they consisted respectively of nutritional therapy, a psychosocial-home-based care intervention, a counselling support intervention to address substance abuse, cervical cancer screening and a rectal microbicide intervention for HIV prevention. It should be noted that two of the studies reviewed assessed more than one intervention ${ }^{45} 52$ ( 3 and 4 , respectively). The total number of interventions assessed for acceptability was, therefore, 60 .

More detail on intervention subtypes is included in online supplemental table 2. For example, E-health interventions included game based, ${ }^{1}$ SMS-based ${ }^{7}$ and 


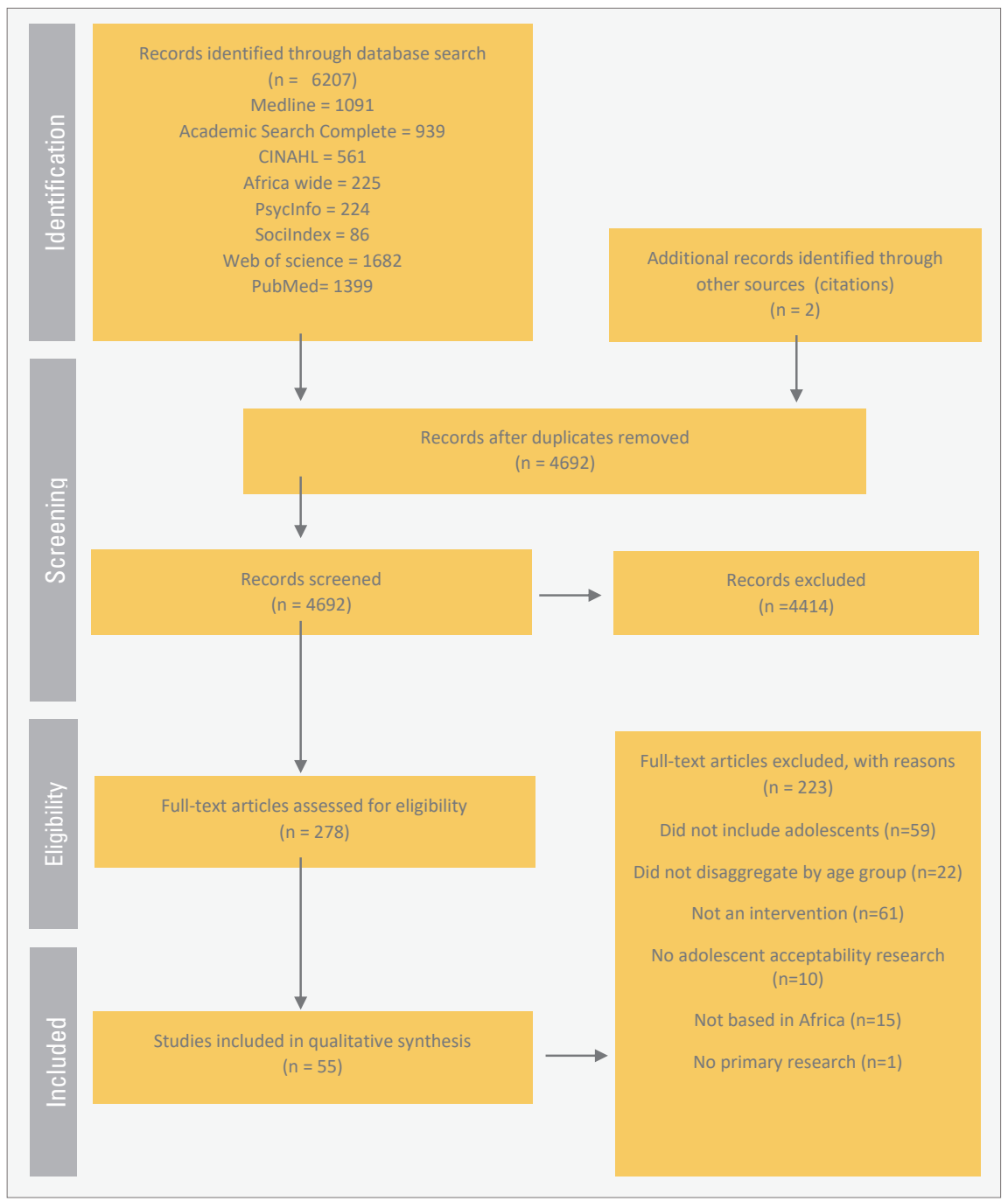

Figure 1: The PRISMA flow diagram describing the process of study selection.

Figure 1 The PRISMA flow diagram describing the process of study selection. PRISMA, Preferred Reporting Items for Systematic Reviews and Meta-Analyses.

internet-based $^{2}$ programmes. All seven support group interventions provided psychosocial or educational support related to HIV, and five worked only with young adults living with HIV. One group intervention was delivered through both a social media platform and in-person meetings, ${ }^{53}$ one was a family based support intervention with adolescent-parent dyads, ${ }^{33}$ four were linked to public healthcare facilities ${ }^{42475455}$ and one was a community intervention. ${ }^{43}$

The primary objectives of most interventions were focused on HIV-related or sexual and reproductive health-related outcomes (see figure 4): 19 primarily aimed to prevent new HIV infections, 10 to prevent human papillomavirus (HPV) infection, 9 to increase HIV treatment adherence and retention in care, 8 to increase the uptake of HIV testing, 8 aimed at increasing contraceptive uptake and reducing early childbearing and 6 provided psychosocial support for adolescents living with HIV.

The objectives of almost all interventions were therefore linked to indicators within SDG3 (ensuring healthy lives and promoting well-being). However, one study could also be linked to SDG2 (food security and improved nutrition), six to SDG4 (inclusive and equitable quality education), eight to SDG5 (gender equality) and one to SDG6 (access to water and sanitation).

\section{Definitions and conceptual frameworks for acceptability}

Only 7 of the 55 reviewed studies provided an explicit definition of acceptability and only 6 used a conceptual framework (as indicated in online supplemental table 2). Three definitions focused on the preference for or willingness to use the intervention: Tonen-Wolyec et $a t^{44}$ defined acceptability as consenting to and using the (HIV 


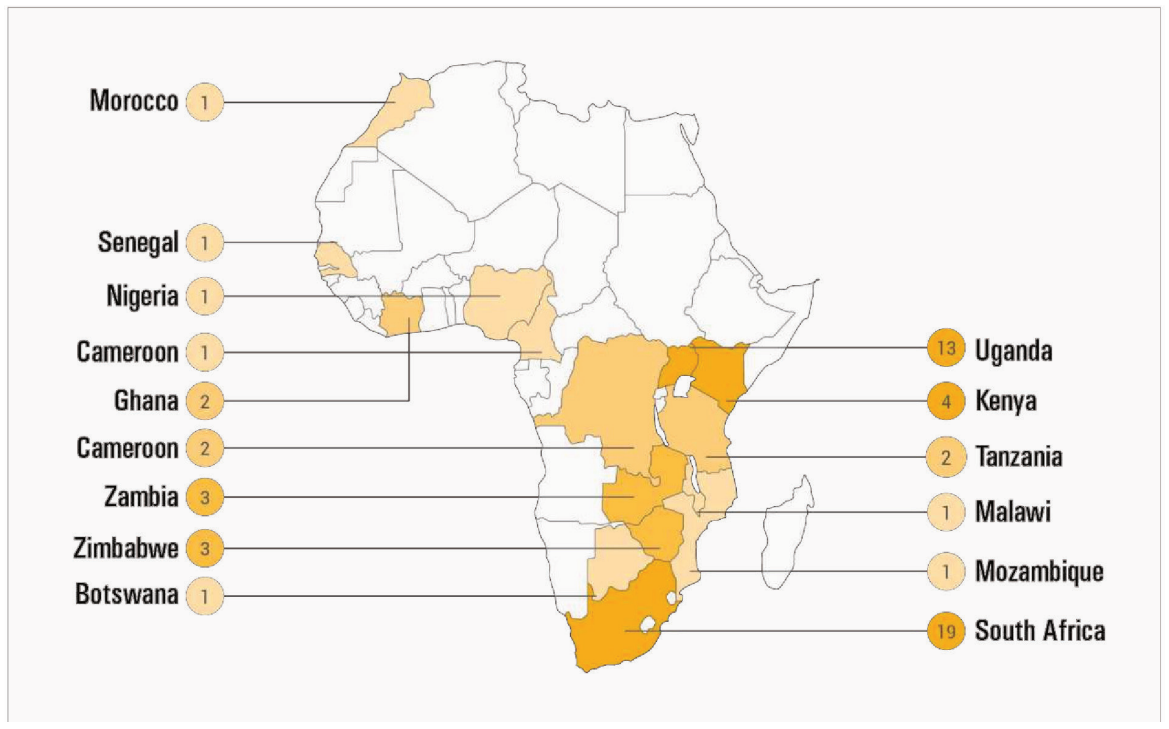

Figure 2 Study location.

\section{Type of Intervention}

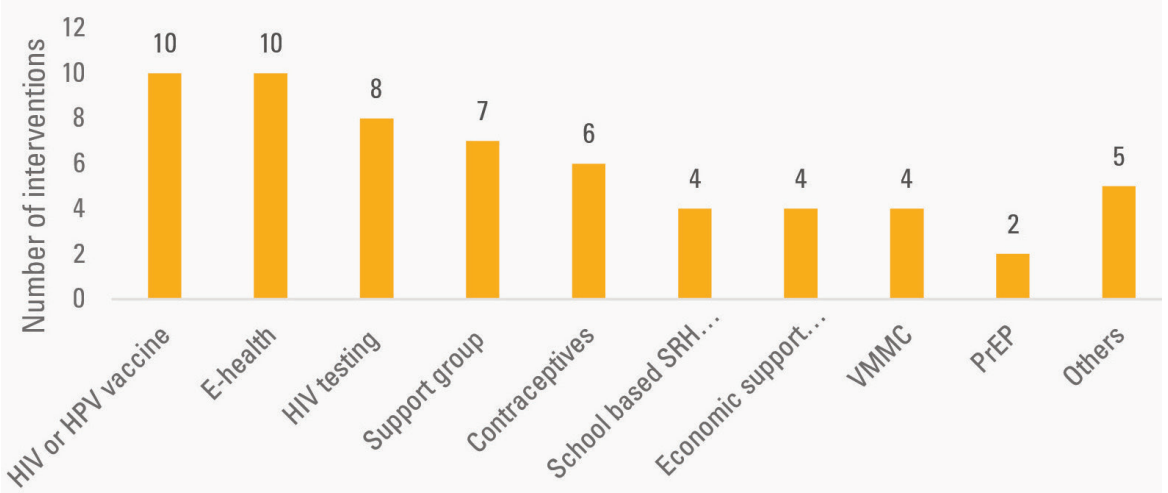

Figure 3 Intervention types. PrEP, pre-exposure prophylaxis; VMMC, voluntary medical male circumcision; HPV, Human papillomavirus.

self-testing) intervention; Smith $e t a l^{30}$ defined it as the preference for using the (HIV self-testing) device; and Katahoire et a $\tilde{p}^{6}$ defined acceptability as the willingness or reluctance to use and complete the intervention (in this case the 3 doses of HPV vaccine).$^{56}$

Two definitions focused mainly on responses to the intervention. MacCarthy et $a t^{48}$ referred to a definition and framework developed by Sekhon et $a t^{20}$ and defined acceptability as the cognitive and emotional responses to an intervention. ${ }^{20}{ }^{48}$ Parker et $a t^{42}$ defined acceptability as how the intended individual recipients react to a programme, guided by the Bowen feasibility framework. ${ }^{57}$ A further two studies conceptualised acceptability as an implementation outcome and focused on value, appeal and likeability: Kibel et a ${ }^{58}$ referred to the perception among stakeholders that a certain element of the programme was valued, agreeable or satisfactory, while Sabben $e t a \ell^{34}$ defined acceptability as appeal, relevance, value, usability and understandability, based on the Technology Acceptance Model's framework. ${ }^{59}$
Three studies referred to a conceptual framework but did not provide an explicit definition of acceptability. In their assessment of individual and environmental barriers and facilitators related to use of a school-based contraception clinic (SBCC), Khoza et $a l^{32}$ referred to the social ecological framework. ${ }^{60}$ Sayles et $a l$ 's study was guided by value-expectancy and social marketing theories ${ }^{61}$; the authors investigated vaccine attitudes, normative vaccine beliefs, and perceived risk and severity of HIV as determinants of HIV vaccine uptake. Turiho et $a l^{\prime}{ }^{62}$ study used the symbolic interactionism theory and some aspects of the Health Beliefs Model to explain how community members' perceptions and their interaction shape vaccine acceptability.

\section{Study design, methods and indicators}

Sixteen studies included in this review (29\%) assessed 'anticipated' or prospective acceptability among adolescents who had not (yet) received the intervention. ${ }^{20}$ Eighteen studies (33\%) assessed acceptability concurrently, 


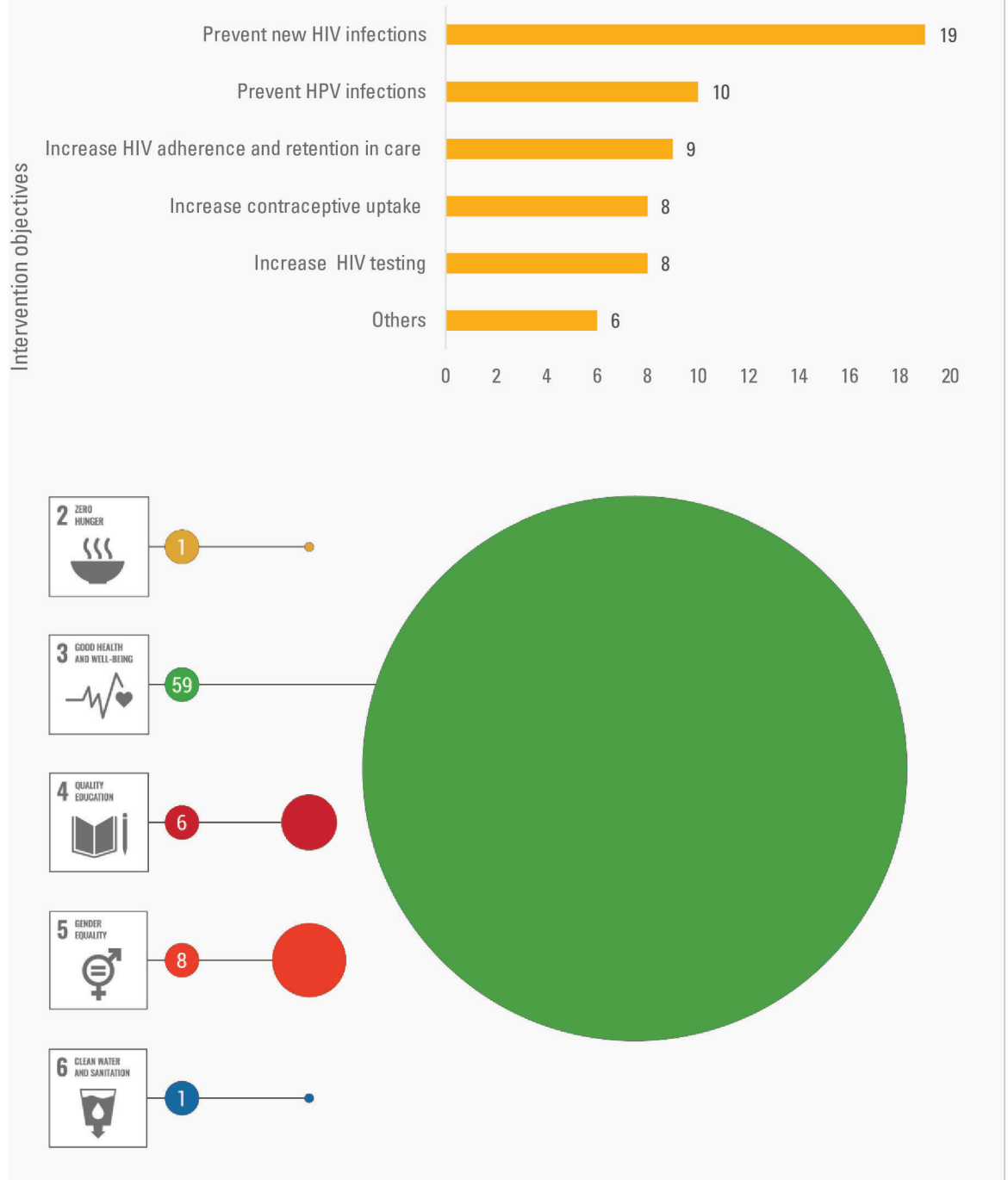

Figure 4 Intervention objectives and number of interventions linked to each SDG. SDG, Sustainable Development Goal.

during the delivery of the intervention, while $14(25 \%)$ assessed acceptability postintervention, retrospectively. The remaining seven $(13 \%)$ of the studies assessed interventions prospectively and retrospectively; among these, two studies worked with separate groups of adolescents who had received and not yet received the intervention, ${ }^{5263}$ while the remaining five interviewed adolescents at two different stages of the intervention. ${ }^{404556465}$ Five studies involved adolescents in the study design. 4350535565

Twenty studies described their methodology as solely qualitative, 18 as quantitative and 17 as mixed methods. Eleven of the qualitative studies used only focus group discussions (FGDS), seven used only in-depth interviews (IDIs) and two used both methods. Most of the quantitative studies ${ }^{15}$ employed structured survey questionnaires. The mixed-methods studies combined FGDs or IDIs with survey questionnaires, online surveys and evaluation reports.

As detailed in online supplemental table 2, wide range of questions and indicators were used to measure acceptability. None of the studies used a standardised previously validated instrument, although two papers drew from existing instruments. ${ }^{66} 67$ The majority of questions asked across studies covered participants' overall perceptions and experience of the intervention, willingness to use the intervention, understanding of the intervention, barriers and facilitators of access and use, the perceived effectiveness of the intervention and willingness to recommend or distribute it to others.

\section{Acceptability findings}

Overall, acceptability of interventions assessed was high. Of the 55 studies, 30 assessed acceptability quantitatively and reported on the proportion of young adults in the sample that found the intervention acceptable. While some studies quantified acceptability through a single percentage, based on one question or indicator, a number of studies reported a range, based on multiple questions or indicators. One of the reviewed studies reported $100 \%$ acceptability, ${ }^{33}$ while acceptability ranged from $64 \%$ to $100 \%$ in 25 studies and $46 \%$ to $61 \%$ in two studies. ${ }^{27} 526869$ Only two studies clearly reported acceptability below $50 \%$ : at $37 \%$ for a contraceptive intervention in Tanzania ${ }^{70}$ and $27 \%$ for an HPV vaccine study in Morocco. ${ }^{71}$ Reasons 
given for low acceptability of the contraceptive intervention were that adolescents and their peers were too young to be sensitised about condoms, that condoms would not be used properly and that using contraception was a $\sin .{ }^{70}$ Reasons were not provided by adolescents for the Moroccan study; however, in quantitative analysis, older age, female gender, studying at a public (vs private) school and lower educational attainment were associated with lower odds of acceptability for the HPV vaccine. ${ }^{71}$

The remaining 25 studies did not quantify acceptability. However, the authors of two of these studies reported that adolescents found the interventions to be unacceptable, based on their overall findings. One study in South Africa assessed contraceptive interventions ${ }^{32}$; a key reason for low acceptability was the belief that an SBCC could promote promiscuity by sending a message that 'teenage sex was acceptable' and making contraceptives easily accessible. ${ }^{32}$ The second study assessed a psychosocial home based care intervention in Tanzania, ${ }^{72}$ which adolescent participants felt did not align well with their expectations. They believed the intervention to be more relevant to their caregivers and were disappointed in the lack of financial support in a context of widespread poverty. ${ }^{72}$

Findings of the remaining 51 studies overall indicated high levels of acceptability. Some of these studies also provided various reasons as to why adolescents found the interventions acceptable $(n=22)$ or (for a minority of adolescents) not acceptable $(n=20)$. These are presented in table 1, by type of intervention, for studies with both low and high overall acceptability. The main reasons e-Health interventions were acceptable to adolescents were: knowledge gained from the intervention regarding their sexual health, ${ }^{3465}$ the privacy these interventions provided ${ }^{2348}$ and knowing how to make use of the intervention. ${ }^{25} 34$ Adolescents who instead did not find these interventions acceptable felt that the content was not culturally appropriate, ${ }^{232565}$ highlighted technological glitches ${ }^{48} 65$ or were concerned with inclusiveness where, for example, not all the young adults had access to a necessary device or risked unintended disclosure of private information when sharing devices. ${ }^{6573}$

Confidentiality, appropriateness, privacy and decisionmaking autonomy were among the reasons adolescents found HIV testing interventions (including self-testing and testing in schools) acceptable. ${ }^{4464}$ Fear of the procedure, concerns with the cost and validity of the test, and inadequate emotional support were reasons given for lack of acceptability. ${ }^{6475}$ Support group interventions were considered acceptable because of the emotional support provided and because young adults found the groups to be empowering and were able to discuss HIVrelated issues in a stigma-free environment. ${ }^{42} 475355$

Knowledge was a key reason for high vaccine acceptability for both HPV and HIV vaccine interventions. For example, adolescents' understanding that HPV vaccines could prevent cervical cancer and HIV made them more likely to accept the interventions. ${ }^{63}$ Conversely, lack of knowledge or understanding of the intervention was linked to low acceptability. ${ }^{3652} 56$ Other reasons given for acceptability were greater female autonomy and agency to protect themselves, in the event of sexual violence or transactional sex and encouragement of peers. ${ }^{3663}$ On the other hand, perceived cost, myths and distrust of vaccine providers, and fear of side effects, were themes raised to explain low acceptability. ${ }^{61} 77$

Reasons for acceptability of economic support interventions included financial autonomy ${ }^{78}$ and the freedom to decide how to use cash transfers. ${ }^{28}$ However, concerns around the process of selecting which individuals or households were to receive transfers, as well as inclusion, sustainability and effects on social relations and social equity within the community, ${ }^{3878}$ were factors that threatened acceptability.

\section{DISCUSSION}

Findings of this review indicate two positive trends. The first is an increase, over the past decade, in the number of acceptability studies with adolescents and youth on the continent. Though numbers are overall low, this could signal increasing recognition of the value of engaging young people when designing and implementing interventions intended for them. The second is that acceptability of interventions assessed was generally high. This suggests an overall good alignment of interventions with adolescent needs and preferences. While studies focusing on acceptability among general adolescent populations are scarce even in HICs, our findings of overall high acceptability were in line with a review on the acceptability of e-mental health services for children, adolescents, and young adults conducted in Canada. ${ }^{79}$ However, we should also be aware of the possibility of publication bias, ${ }^{80} 81$ as research showing less favourable acceptability results may be less likely to be written up and published.

A key limitation of this review is that we did not include grey literature, given available resources, the review's already broad scope, and to ensure a minimum quality of studies included. We also did not include studies published before 2010 and after June 2020, or studies that weren't published in English, so the review may have excluded relevant studies outside of this time period or carried out in African countries where English is not the (only) official language. We also did not conduct a quality assessment, given the heterogeneity of interventions assessed and study designs; however, we note that this is not a requirement of a mapping review, which aims to summarise available evidence in an area vs focus on a particular research question. ${ }^{82-84}$

\section{Acceptability findings}

Despite the diversity of intervention settings, types of interventions and modes of delivery across studies, several common themes emerged from reasons given by adolescents to explain why specific interventions were acceptable to them. These included the product or intervention being easy to use, knowledge of the intervention 
Table 1 Reasons provided by adolescents for acceptability and unacceptability of interventions, by type of intervention

\section{Type of} intervention

\begin{tabular}{ll}
\hline eHealth & Knowledge provided on sexual health and HIV25 34 \\
& Privacy $^{2348}$
\end{tabular}

\begin{tabular}{|c|c|}
\hline & Increased self-efficacy to manage risky situations ${ }^{34}$ \\
\hline & Ease of use $\mathrm{s}^{34}$ \\
\hline & Supportive mentors ${ }^{29}$ \\
\hline & $\begin{array}{l}\text { Freedom to talk openly to mentors about HIV status } \\
\text { and disclosure }\end{array}$ \\
\hline Vaccines & $\begin{array}{l}\text { Protection from HPV in the case of sexual abuse or } \\
\text { transactional sex } \mathrm{s}^{36}\end{array}$ \\
\hline & $\begin{array}{l}\text { Protection from HIV infection when the transmission } \\
\text { risk is out of an individual's control }{ }^{4561}\end{array}$ \\
\hline & $\begin{array}{l}\text { Desire to have unprotected sex for childbearing } \\
\text { (women on HIV-vaccine) })^{61}\end{array}$ \\
\hline & $\begin{array}{l}\text { Being able to have unprotected sex and multiple } \\
\text { sexual partners (male adolescents on HIV vaccine) }\end{array}$ \\
\hline & $\begin{array}{l}\text { Protection in serodiscordant relationships while } \\
\text { avoiding the HIV stigma and costs related to buying } \\
\text { condoms } \\
\text { (male adolescents on HIV vaccine) }^{45}\end{array}$ \\
\hline
\end{tabular}

\section{Hiv testing}

HIV testing

\begin{tabular}{|c|c|c|}
\hline & Ease of use of HIV self-test ${ }^{44} 76$ & Costs of HIV test kit ${ }^{64}$ \\
\hline & Fast results of self-test ${ }^{44}$ & Lack of emotional support with self-test ${ }^{64} 76$ \\
\hline & Ability to test independently with self-test ${ }^{64}$ & Fear of the procedure (finger prick) $)^{3075}$ \\
\hline & $\begin{array}{l}\text { Opportunity to know HIV status, for peace of mind } \\
\text { and to plan for the future (provider-initiated testing) }\end{array}$ & $\begin{array}{l}\text { Belief that school is not the right place for HIV } \\
\text { testing }^{74}\end{array}$ \\
\hline & $\begin{array}{l}\text { Lower waiting time, less distance to facility, and } \\
\text { friendlier staff at mobile (vs 'conventional') clinic }\end{array}$ & $\begin{array}{l}\text { Lack of privacy and risk of stigma through school } \\
\text { testing }^{74}\end{array}$ \\
\hline \multirow[t]{6}{*}{ Support group } & Emotional and social support provided ${ }^{42475355}$ & \\
\hline & Knowledge and skills provided ${ }^{4255}$ & \\
\hline & Enjoyed participating ${ }^{53}$ & \\
\hline & Stigma free environment ${ }^{54}$ & \\
\hline & $\begin{array}{l}\text { Confidential space to openly discuss sexual health } \\
\text { and behaviour }{ }^{4253}\end{array}$ & \\
\hline & $\begin{array}{l}\text { Greater decision-making autonomy to negotiate } \\
\text { safer sexual relationships }\end{array}$ & \\
\hline \multirow[t]{3}{*}{ SRH education } & $\begin{array}{l}\text { Increased knowledge on sexual and reproductive } \\
\text { health }^{24} 41\end{array}$ & $\begin{array}{l}\text { Conservative views about certain topics discussed } \\
\text { (linked to sexual intercourse) }{ }^{41}\end{array}$ \\
\hline & Supportive teachers at youth clubs ${ }^{41}$ & \\
\hline & $\begin{array}{l}\text { Girls more comfortable attending school during } \\
\text { menstruation }^{24}\end{array}$ & \\
\hline
\end{tabular}

\section{Reasons given for unacceptability}

Visual content considered not culturally appropriate ${ }^{23}$

Conservative views about certain topics discussed (eg, oral sex) $)^{25} 65$

Concerns around access and inclusiveness, as not all youth owned devices ${ }^{6573}$

Fear of accidental disclosure of confidential information through device-sharing ${ }^{73}$

Technical glitches with devices ${ }^{4865}$

Distrust of government and scientists ${ }^{61}$

Association of vaccine uptake with promiscuity ${ }^{61}$

Fear of HIV testing and HIV stigma ${ }^{61}$

Cost of vaccine $e^{61}$

Fear of vaccine side effects ${ }^{51616377}$

Fear of injection ${ }^{77}$

Lack of knowledge about vaccine and cervical cancer $^{36} 5256$

Concern with validity of HIVST self-test kit results ${ }^{64}$ 76

Costs of HIV test kit ${ }^{64}$

Lack of emotional support with self-test ${ }^{6476}$

Belief that school testing

Lack of privacy and risk of stigma through school

Continued 


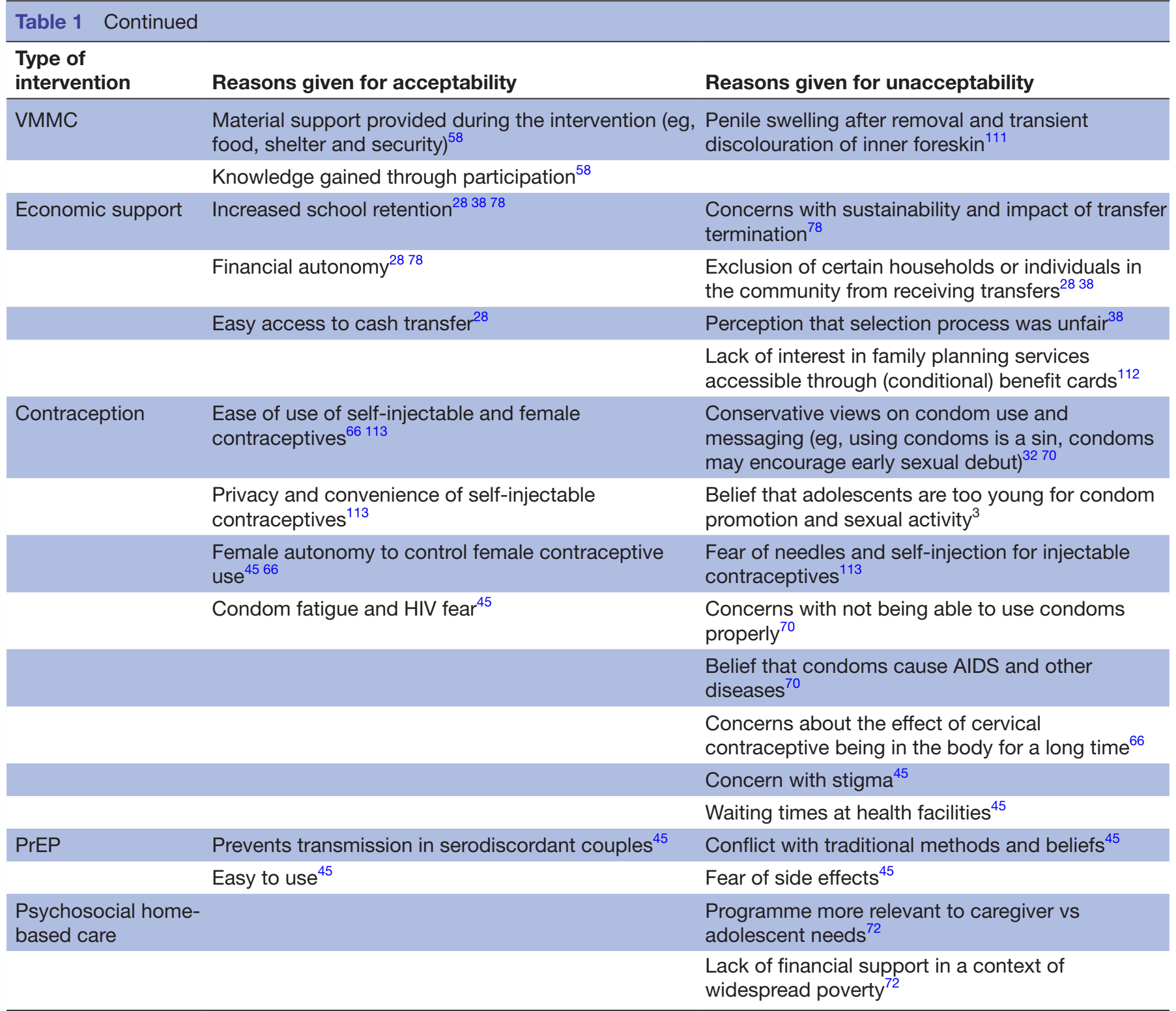

PrEP, pre-exposure prophylaxis; VMMC, voluntary medical male circumcision.

or knowledge provided by the intervention, the intervention allowing for (greater) autonomy, adolescents feeling supported while participating in the intervention and feeling assured that their privacy and confidential information would be protected. Ease of use ${ }^{85} 86$ and support received $^{87}$ from the intervention were reasons for acceptability in HICs. Although reasons for 'unacceptability' were more diverse, overarching themes could also be identified among these, for example, conservative views about the intervention or its content; concerns around intervention costs, access and inclusiveness; fear of pain and side effects (for biomedical interventions); stigma, myths or distrust; and lack of knowledge or support. The cost ${ }^{88}$ of interventions, pain ${ }^{89}$ and conservative views about the intervention ${ }^{90}$ have also been outlined as reasons for unacceptability among adolescents and youth in LMIC and HICs. While certain drivers of unacceptability mirrored those of acceptability (eg, knowledge and support), these drivers mostly differed, suggesting that acceptability and unacceptability are not necessarily represented by one continuum.

These findings suggest that intervention developers and implementers across the continent should pay attention to key aspects of interventions and their delivery that adolescents clearly care about and seek to address these from the intervention development phase. They should ensure that adolescents are provided with adequate knowledge, training and resources to properly understand the intervention and feel confident in their ability to use it and that they have access to sufficient logistical and emotional support while participating. They should also ensure that these young people's confidential information is protected, so that they are in turn protected from much-feared stigma and other potential negative social 
consequences. Moreover, they should bear in mind that adolescents value autonomy and that this has a gender dimension. Autonomy relates not only to being able to choose to participate in and use an intervention, but also being empowered by the knowledge it may provide and the greater control it may afford young people (particularly young women) in managing high-risk situations and unequal relationships.

It may also be worth paying particular attention to acceptability findings for specific types of interventions, given current African and global public health challenges. For example, the role of digital technology in achieving many of the SDGs is well documented ${ }^{91}$ and merits particular attention in the context of the COVID-19 pandemic. $^{92} 93$ While young people remain the most connected population group to digital platforms, ${ }^{94}$ there is a clear digital divide, as more than $60 \%$ of young adults in Africa do not have access to internet. ${ }^{95}{ }^{96}$ Findings of this review show overall high acceptability of e-Health interventions, ${ }^{34} 50$ as adolescents highlighted opportunities presented by digital technology, for example, by reducing the cost of in-person interaction. ${ }^{53}$ Yet concerns raised around connectivity issues, lack of access to devices and unintended disclosure of confidential information $^{53} 73$ represent challenges for the acceptability, equitable access and effectiveness of e-Health programmes. It is, therefore, important for intervention providers to assess these challenges early on, and to explore ways of potentially increasing access to devices or technologies within the intervention itself or by supporting concurrent initiatives. ${ }^{65}$

Low acceptability of several interventions aimed at increasing contraceptive use and HIV testing also merits particular attention. HIV transmission and relatively low rates of HIV testing and linkage to antiretroviral therapy remain a concern among young adults. ${ }^{9798}$ Several studies included in this review highlighted, for example, adolescents' fear of stigma and lack of privacy regarding HIV testing interventions in schools, ${ }^{74}$ concerns about not being able to properly perform oral HIV testing on their $\mathrm{own}^{76}$ and conservative views of contraceptive promotion and use. ${ }^{3270}$ These perspectives are likely shaped by inadequate understanding of interventions, but also by social norms surrounding sexuality and contraception within adolescents' homes, schools and communities. ${ }^{99} 100$ Also, fear of vaccines and their side effects ${ }^{101} 102$ are important to note and address, in relation not only to HPV prevention, but also to the current COVID-19 vaccine roll-out.

All of the above examples highlight the importance of strengthening adolescents' knowledge of interventions and how to interact with them, but also of understanding and engaging with the broader context within which adolescent acceptability is shaped. ${ }^{99}$ One way to achieve this is to involve adolescents (preferably potential end-users) early in the design and planning phase of the intervention and-if possible-at various stages of the intervention life cycle. Yet, as indicated above, less than half of the studies in this review (42\%) assessed prospective acceptability and very few studies involved adolescents in the study design and/or at multiple phases of the intervention. There is clearly potential to allow for more meaningful and consistent adolescent engagement, if young people are to have a stronger role in shaping the development, adaptation and scale up of interventions. ${ }^{20}$

A second key approach would be to engage early on and assess acceptability with other stakeholders who are central to an intervention being well-targeted, well-implemented and accepted by adolescents and the broader community. These may include intervention implementers and facilitators, but also caregivers, partners and peers, teachers and community leaders. As noted above, 25 studies in this review also assessed acceptability of other types of stakeholders. Future review analyses and acceptability studies could further focus on acceptability among these groups of individuals, and its implications for adolescent acceptability and intervention success.

\section{Gaps and key areas for future research}

Our review highlights several key gaps and related areas for future intervention acceptability research. First, there appears to be a gap in geographical coverage, particularly in West, Central and North Africa. However, as noted above, confining our search to English language publications may have excluded some studies from African countries where French is the first language. Given that adolescent needs and preferences are likely to differ across areas with very different social and cultural norms and faith contexts, ${ }^{103}$ we cannot simply extrapolate acceptability findings to other countries or communities across the continent.

Second, there is clearly scope for more acceptability research in important areas for adolescent development beyond (physical) health and, within the health sector, beyond HIV. As important as reducing HIV transmission and increasing testing and treatment adherence may be in this population, ${ }^{9798}$ they are clearly not the only dimensions of adolescent health and broader well-being that merit attention and investment. There is a glaring lack of acceptability studies in areas of adolescent development beyond SDG 3. These include education access and outcomes, employment opportunities, access to water and other services, gender equality and protection from violence, social protection and mental health. ${ }^{104}$

The focus on specific types of interventions likely reflects, to a large extent, global health funding and research priorities over the past decades. There has been a considerable amount of international aid dedicated to addressing HIV ${ }^{105} 106$ and particular concern around the acceptability of HIV interventions. Moreover, the concentration of acceptability research in specific countries in Africa is likely in part a reflection of disparities in independent research infrastructure and capacity across the continent. ${ }^{107108}$ It would also seem that 'acceptability' is a concept and term that has gained traction primarily within the health sector. ${ }^{20}$ The extension of acceptability research to geographical and developmental areas where 
it is currently scarce therefore cannot be addressed solely by decisions of individual research teams. It will to some extent require a change in global health and funding priorities, and the 'adoption' of acceptability research by other sectors.

A third gap highlighted by this review is the considerable scope to further conceptualise the construct of acceptability, by more clearly defining it and identifying its key components. Our review reinforced the absence of a clear or standard definition of acceptability, or common tools and indicators. In fact, the large majority of papers included in this review ${ }^{48}$ referred to the concept of acceptability without defining it at all, requiring the reader to review the questions and indicators used to gain some understanding of how the construct of acceptability was conceptualised and operationalised. As highlighted by other authors, this lack of common definitions and frameworks makes the selection of measurement indicators for empirical enquiry in this area more difficult and the comparability of acceptability results challenging. ${ }^{109110}$ There have been recent efforts to address these gaps; in particular, Sekhon et al s theoretical framework for acceptability, published in $2017,{ }^{20}$ has made a valuable contribution to the scarce conceptual literature in the field. However, there is still much work to be done to apply and test the framework in specific populations. For example, its relevance and completeness in investigating acceptability among adolescents, in less-resourced settings and beyond the (biomedical) health sector is still unclear. Also unclear is the important link between intervention acceptability and uptake, considering that willingness to use the intervention is often included among questions used to assess acceptability (see online supplemental table 2). Lastly, it is encouraging to note that a relatively large number of studies in our review used mixed-methods approaches to assess acceptability; however, there is clearly still scope to employ and combine more innovative methodologies. ${ }^{5565}$

\section{CONCLUSION}

As the first systematic review to aggregate and synthesise a decade of acceptability studies with adolescents and youth in Africa, we believe this study makes a valuable contribution to the African and global literature on acceptability. It highlights the overall high level of acceptability of the interventions assessed, and some of the reasons why adolescents and young adults may or may not find interventions acceptable-both specific to particular types of interventions and common across intervention types.

However, it also exposes considerable scope for future acceptability research and review work, to extend and strengthen the existing body of evidence. This should include extending acceptability research beyond the health (and particularly HIV) sector and to countries in Africa where this type of research is still scarce; including adolescents and other potential key stakeholders earlier, and potentially throughout, the intervention process; further conceptualising the construct of acceptability and investigating the relationship between acceptability and intervention uptake and success.

\section{Author affiliations}

${ }^{1}$ UKRI GCRF Accelerating Achievement for Africa's Adolescents, School of Public Health, , University of the Western Cape, Cape Town, South Africa

${ }^{2}$ Department of Social Policy and Intervention, University of Oxford, Oxford, UK ${ }^{3}$ Centre for Social Science Research, University of Cape Town, Cape Town, South Africa

${ }^{4}$ Centre for Rural Health, University of KwaZulu-Natal, KwaZulu-Natal, South Africa ${ }^{5}$ Dept of Psychiatry and Mental Health, University of Cape Town, Cape Town, South Africa

${ }^{6}$ University College London, London, UK

Acknowledgements $\mathrm{OS}, \mathrm{MC}, \mathrm{GHR}, \mathrm{CD}, \mathrm{LC}$ and $\mathrm{LS}$ receive funding from the UKR GCRF Accelerating Achievement for Africa's Adolescents (Accelerate) Hub (Grant Ref: ES/S008101/1) and the 0ak Foundation: (Grant Number R46194/AA001)

Contributors ODS and MC were involved in the conceptualisation of the paper, the data extraction and analysis, and the manuscript writing; GHR was part of the data extraction and analysis, and reviewed and revised the manuscript; CD reviewed and revised the manuscript; LC reviewed and revised the manuscript; and LS reviewed and revised the manuscript. All authors read, reviewed and approved the final manuscript. ODS accepts full responsibility for the work and conduct of the study.

Funding Funding received from the South African Research Chair in Health Systems, Complexity and Social Change supported by the South African Research Chair's Initiative of the Department of Science and Technology and National Research Foundation of South Africa (Grant No 82769). Any opinion, finding and conclusion or recommendation expressed in this material is that of the author and the NRF does not accept any liability in this regard.

Map disclaimer The depiction of boundaries on this map does not imply the expression of any opinion whatsoever on the part of BMJ (or any member of its group) concerning the legal status of any country, territory, jurisdiction or area or of its authorities. This map is provided without any warranty of any kind, either express or implied.

Competing interests None declared.

Patient consent for publication Not applicable.

Provenance and peer review Not commissioned; externally peer reviewed.

Data availability statement All data relevant to the study are included in the article or uploaded as online supplemental information.

Supplemental material This content has been supplied by the author(s). It has not been vetted by BMJ Publishing Group Limited (BMJ) and may not have been peer-reviewed. Any opinions or recommendations discussed are solely those of the author(s) and are not endorsed by BMJ. BMJ disclaims all liability and responsibility arising from any reliance placed on the content. Where the content includes any translated material, BMJ does not warrant the accuracy and reliability of the translations (including but not limited to local regulations, clinical guidelines, terminology, drug names and drug dosages), and is not responsible for any error and/or omissions arising from translation and adaptation or otherwise.

Open access This is an open access article distributed in accordance with the Creative Commons Attribution Non Commercial (CC BY-NC 4.0) license, which permits others to distribute, remix, adapt, build upon this work non-commercially, and license their derivative works on different terms, provided the original work is properly cited, appropriate credit is given, any changes made indicated, and the use is non-commercial. See: http://creativecommons.org/licenses/by-nc/4.0/.

ORCID iD

Oluwaseyi Dolapo Somefun http://orcid.org/0000-0002-3842-2685

\section{REFERENCES}

1 Cluver LD, Orkin FM, Meinck F, et al. Can social protection improve sustainable development goals for adolescent health? PLoS One 2016;11:e0164808.

2 Bhutta ZA, Yount KM, Bassat Q, et al. Revisiting child and adolescent health in the context of the sustainable development 
goals. San Francisco, CA USA: Public Library of Science, 2020: 17. e1003449.

3 Sheehan P, Sweeny K, Rasmussen B, et al. Building the foundations for sustainable development: a case for global investment in the capabilities of adolescents. The Lancet 2017;390:1792-806.

4 United Nations Department of Economic Social Affairs UN. 2019 revision of World population prospects; 2019.

5 Tiwari S, Daidone S, Ruvalcaba MA, et al. Impact of cash transfer programs on food security and nutrition in sub-Saharan Africa: a cross-country analysis. Glob Food Sec 2016;11:72-83.

6 Kilburn K, Ferrone L, Pettifor A, et al. The Impact of a Conditional Cash Transfer on Multidimensional Deprivation of Young Women: Evidence from South Africa's HTPN 068. Soc Indic Res 2020;151:865-95

7 Super S, Hermens N, Verkooijen K, et al. Examining the relationship between sports participation and youth developmental outcomes for socially vulnerable youth. BMC Public Health 2018;18:1012.

8 World Health Organization. Why invest in adolescent health? 2021. Available: https://www.who.int/maternal_child_adolescent/topics/ adolescence/why-invest/en/

9 Dahl RE, Allen NB, Wilbrecht L, et al. Importance of investing in adolescence from a developmental science perspective. Nature 2018;554:441-50.

10 Lutz W, Crespo Cuaresma J, Kebede E, et al. Education rather than age structure brings demographic dividend. Proc Natl Acad Sci U S A 2019;116:12798-803.

11 Bongaarts J, Gragnolati M, Ahmed S. Development. and policy 2020.

12 Salam RA, Das JK, Lassi ZS, et al. Adolescent health interventions: conclusions, evidence gaps, and research priorities. J Adolesc Health 2016;59:S88-92.

13 Chandra-Mouli V, Lane C, Wong S. What does not work in adolescent sexual and reproductive health: a review of evidence on interventions commonly accepted as best practices. Global Health: Science and Practice 2015;3:333.

14 World Health Organization. Global standards for quality healthcare services for adolescents: a guide to implement a standardsdriven approach to improve the quality of health care services for adolescents; 2015

15 Malti T, Noam GG, Beelmann A, et al. Toward dynamic adaptation of psychological interventions for child and adolescent development and mental health. Journal of Clinical Child \& Adolescent Psychology 2016;45:827-36.

16 Patton GC, Sawyer SM, Ross DA, et al. From advocacy to action in global adolescent health. Journal of Adolescent Health 2016;59:375-7.

17 Burt MR. Reasons to invest in adolescents. $J$ Adolesc Health 2002;31:136-52.

18 Stok FM, de Ridder DTD, de Vet E, et al. Hungry for an intervention? Adolescents' ratings of acceptability of eating-related intervention strategies. BMC Public Health 2015;16:5.

19 Silva MR, Collier-Meek MA, Codding RS, et al. Acceptability assessment of school psychology interventions from 2005 to 2017. Psychology in the Schools 2020;57:62-77.

20 Sekhon M, Cartwright M, Francis JJ. Acceptability of healthcare interventions: an overview of reviews and development of a theoretical framework. BMC Health Serv Res 2017;17:88.

21 Yeager DS, Dahl RE, Dweck CS. Why interventions to influence adolescent behavior often fail but could succeed. Perspectives on Psychological Science 2018;13:101-22.

22 O'Connor D, Green S, Higgins JP. Defining the review question and developing criteria for including studies. Cochrane handbook for systematic reviews of interventions: Cochrane book series, 2008: 81-94.

23 Bull S, Nabembezi D, Birungi R, et al. Cyber-Senga: Ugandan youth preferences for content in an internet-delivered comprehensive sexuality education programme. East Afr J Public Health 2010;7:58-63.

24 Kansiime C, Hytti L, Nalugya R, et al. Menstrual health intervention and school attendance in Uganda (MENISCUS-2): a pilot intervention study. BMJ Open 2020;10:e031182.

25 Ybarra ML, Bull SS, Prescott TL, et al. Acceptability and feasibility of CyberSenga: an Internet-based HIV-prevention program for adolescents in Mbarara, Uganda. AIDS Care 2014;26:441-7.

26 Herman L, Ovuga E, Mshilla M, et al. Knowledge, perceptions and acceptability to strengthening adolescents' sexual and reproductive health education amongst secondary schools in Gulu district. World Acad Sci Eng Technol 2013;7:1787-802.

27 Mitchell KJ, Bull S, Kiwanuka J, et al. Cell phone usage among adolescents in Uganda: acceptability for relaying health information. Health Educ Res 2011;26:770-81.
28 Banda E, Svanemyr J, Sandøy IF, et al. Acceptability of an economic support component to reduce early pregnancy and school dropout in Zambia: a qualitative case study. Glob Health Action 2019:12:1685808-11.

29 Hacking D, Mgengwana-Mbakaza Z, Cassidy T, et al. Peer mentorship via mobile phones for newly diagnosed HIV-positive youths in clinic care in Khayelitsha, South Africa: mixed methods study. J Med Internet Res 2019;21:e14012.

30 Smith P, Wallace M, Bekker LG. Adolescents' experience of a rapid HIV self-testing device in youth-friendly clinic settings in Cape town South Africa: a cross-sectional community based usability study. Journal of the International Aids Society 2016;19.

31 Ayissi CA, Wamai RG, Oduwo GO, et al. Awareness, acceptability and uptake of human papilloma virus vaccine among Cameroonian school-attending female adolescents. J Community Health 2012;37:1127-35.

32 Khoza N, Zulu P, Shung-King M. Acceptability and feasibility of a school-based contraceptive clinic in a low-income community in South Africa. Prim Health Care Res Dev 2019;20:N.PAG-N.PAG.

33 Kuo C, Mathews C, Giovenco D, et al. Acceptability, feasibility, and preliminary efficacy of a Resilience-Oriented family intervention to prevent adolescent HIV and depression: a pilot randomized controlled trial. AIDS Educ Prev 2020;32:67-81.

34 Sabben G, Mudhune V, Ondeng'e K, et al. A smartphone game to prevent HIV among young Africans (Tumaini): assessing intervention and study acceptability among adolescents and their parents in a randomized controlled trial. JMIR Mhealth Uhealth 2019;7:e13049.

35 Carney T, Johnson K, Carrico A. Acceptability and feasibility of a brief substance use intervention for adolescents in Cape town, South Africa: a pilot study. International journal of psychology: Journal international de psychologie 2020.

36 Katz IT, Nkala B, Dietrich J, et al. A qualitative analysis of factors influencing HPV vaccine uptake in Soweto, South Africa among adolescents and their caregivers. PLoS One 2013;8:e72094.

37 Niasse F, Varloteaux M, Diop K, et al. Adherence to ready-to-use food and acceptability of outpatient nutritional therapy in HIVinfected undernourished Senegalese adolescents: research-based recommendations for routine care. BMC Public Health 2020;20.

38 MacPhail C, Adato M, Kahn K, et al. Acceptability and feasibility of cash transfers for HIV prevention among adolescent South African women. AIDS Behav 2013;17:2301-12.

39 Ferrand RA, Trigg C, Bandason T, et al. Perception of risk of vertically acquired HIV infection and acceptability of providerinitiated testing and counseling among adolescents in Zimbabwe. Am J Public Health 2011;101:2325-32.

40 Jayeoba O, Dryden-Peterson S, Okui L, et al. Acceptability of male circumcision among adolescent boys and their parents, Botswana. AIDS Behav 2012;16:340-9.

41 Chirwa-Kambole E, Svanemyr J, Sandøy I, et al. Acceptability of youth clubs focusing on comprehensive sexual and reproductive health education in rural Zambian schools: a case of central Province. BMC Health Serv Res 2020;20.

42 Parker L, Maman S, Pettifor A, et al. Feasibility analysis of an evidence-based positive prevention intervention for youth living with HIV/AIDS in Kinshasa, Democratic Republic of the Congo. AIDS Educ Prev 2013;25:135-50.

43 Knopf A, Agot K, Sidle J, et al. "This is the medicine:" A Kenyan community responds to a sexual concurrency reduction intervention. Soc Sci Med 2014:108:175-84.

44 Tonen-Wolyec S, Batina-Agasa S, Muwonga J, et al. Acceptability, feasibility, and individual preferences of blood-based HIV selftesting in a population-based sample of adolescents in Kisangani, Democratic Republic of the Congo. PLoS One 2019;14:e0218795.

45 Atujuna M, Newman PA, Wallace M, et al. Contexts of vulnerability and the acceptability of new biomedical HIV prevention technologies among key populations in South Africa: a qualitative study. PLoS One 2018;13:e0191251-17.

46 Giovenco D, Kuo C, Underhill K, et al. "The Time Has Arrived": Perceptions of Behavioral Adjustments in the Context of PreExposure Prophylaxis Availability Among Adolescents in South Africa. AIDS Educ Prev 2018;30:463-73.

47 James S, Martin CE, Moalusi B, et al. Integrated access to care and treatment (I act) support groups for adolescents living with HIV in public healthcare facilities in South Africa: feasibility and acceptability for scaling up. AIDS Care 2018;30:1107-13.

48 MacCarthy S, Wagner Z, Mendoza-Graf A, et al. A randomized controlled trial study of the acceptability, feasibility, and preliminary impact of SITA (SMS as an incentive to adhere): a mobile technology-based intervention informed by behavioral economics to improve art adherence among youth in Uganda. BMC Infect Dis 2020;20:1-10. 
49 Tabong PT-N, Maya ET, Adda-Balinia T, et al. Acceptability and stakeholders perspectives on feasibility of using trained psychologists and health workers to deliver school-based sexual and reproductive health services to adolescents in urban Accra, Ghana. Reprod Health 2018;15:122.

50 Laidlaw R, Dixon D, Morse T, et al. Using participatory methods to design an mHealth intervention for a low income country, a case study in Chikwawa, Malawi. BMC Med Inform Decis Mak 2017;17:1-12

51 Turiho AK, Okello ES, Muhwezi WW, et al. Perceptions of human papillomavirus vaccination of adolescent schoolgirls in Western Uganda and their implications for acceptability of HPV vaccination: a qualitative study. BMC Res Notes 2017;10:431.

52 Mburu A, Itsura P, Mabeya $\mathrm{H}$, et al. Knowledge of cervical cancer and acceptability of prevention strategies among human Papillomavirus-Vaccinated and human PapillomavirusUnvaccinated adolescent women in Eldoret, Kenya. Biores Open Access 2019;8:139-45.

53 Dulli L, Ridgeway K, Packer C, et al. A social Media-Based support group for youth living with HIV in Nigeria (smart connections): randomized controlled trial. J Med Internet Res 2020;22:e18343.

54 Barker D, Enimil A, Galárraga O, et al. In-Clinic adolescent peer group support for engagement in sub-Saharan Africa: a feasibility and acceptability trial. J Int Assoc Provid AIDS Care 2019;18:232595821983578-8.

55 Snyder K, Wallace M, Duby Z, et al. Preliminary results from Hlanganani (coming together): a structured support group for HIV-infected adolescents piloted in Cape town, South Africa. Child Youth Serv Rev 2014;45:114-21.

56 Katahoire AR, Wani JA, Murokora D. Acceptability of HPV vaccine among young adolescent girls in Uganda: Young people's perspectives count. International Journal of Child and Adolescent Health 2013;6:211-9.

57 Bowen DJ, Kreuter M, Spring B, et al. How we design feasibility studies. Am J Prev Med 2009;36:452-7.

58 Kibel M, Shah P, Ayuku D, et al. Acceptability of a pilot intervention of voluntary medical male circumcision and HIV education for street-connected youth in Western Kenya. Journal of Adolescent Health 2019;64:43-8.

59 Davis FD. User acceptance of information technology: system characteristics, user perceptions and behavioral impacts. Int J Man Mach Stud 1993;38:475-87

60 Golden SD, Earp JAL. Social ecological approaches to individuals and their contexts: twenty years of health education \& behavior health promotion interventions. Health Educ Behav 2012;39:364-72.

61 Sayles JN, Macphail CL, Newman PA, et al. Future HIV vaccine acceptability among young adults in South Africa. Health Educ Behav 2010;37:193-210.

62 Jeon Y-H. The application of grounded theory and symbolic interactionism. Scand J Caring Sci 2004;18:249-56.

63 Turiho AK, Okello ES, Muhwezi WW. Effect of school-based human papillomavirus (HPV) vaccination on adolescent girls' knowledge and acceptability of the HPV vaccine in Ibanda district in Uganda. Afr J Reprod Health 2014;18:45-53.

64 Ritchwood TD, Selin A, Pettifor A, et al. HIV self-testing: South African young adults' recommendations for ease of use, test kit contents, accessibility, and supportive resources. BMC Public Health 2019;19.

65 Ybarra ML, Agaba E, Chen E. Iterative development of in this toGether, the first mHealth HIV prevention program for older adolescents in Uganda. AIDS Behav 2020.

66 van der Straten A, Sahin-Hodoglugil N, Clouse K, et al. Feasibility and potential acceptability of three cervical barriers among vulnerable young women in Zimbabwe. J Fam Plann Reprod Health Care 2010;36:13-19.

67 Smith P, Tolla T, Marcus R, et al. Mobile sexual health services for adolescents: investigating the acceptability of youth-directed mobile clinic services in Cape town, South Africa. BMC Health Serv Res 2019;19:N.PAG-N.PAG.

68 Peltzer K, Mlambo M. Prevalence and acceptability of male circumcision among young men in South Africa. Studies on EthnoMedicine 2012;6:179-86.

69 Cele MA, Archary M. Acceptability of short text messages to support treatment adherence among adolescents living with HIV in a rural and urban clinic in KwaZulu-Natal. South Afr J HIV Med 2019;20:976.

70 Exavery A, Mubyazi GM, Rugemalila J, et al. Acceptability of condom promotion and distribution among 10-19 year-old adolescents in Mpwapwa and Mbeya rural districts, Tanzania. BMC Public Health 2012;12:569.
71 Zouheir Y, Daouam S, Hamdi S, et al. Knowledge of human papillomavirus and acceptability to vaccinate in adolescents and young adults of the Moroccan population. J Pediatr Adolesc Gynecol 2016;29:292-8.

72 Busza J, Besana GVR, Mapunda P, et al. Meeting the needs of adolescents living with HIV through home based care: lessons learned from Tanzania. Child Youth Serv Rev 2014;45:137-42.

73 Rana Y, Haberer J, Huang H, et al. Short message service (SMS)-based intervention to improve treatment adherence among HIV-positive youth in Uganda: focus group findings. PLoS One 2015;10:e0125187.

74 Madiba S, Mokgatle M. "Students want HIV testing in schools" a formative evaluation of the acceptability of HIV testing and counselling at schools in Gauteng and North West provinces in South Africa. BMC Public Health 2015;15:1-9.

75 Shanaube K, Schaap A, Chaila MJ, et al. Community intervention improves knowledge of HIV status of adolescents in Zambia: findings from HPTN 071-PopART for youth study. AIDS 2017;31 Suppl 3:S221-32

76 Hector J, Davies M-A, Dekker-Boersema J, et al. Acceptability and performance of a directly assisted oral HIV self-testing intervention in adolescents in rural Mozambique. PLoS One 2018;13:e0195391.

77 Hoque ME, Ghuman S, Hal GV, Van Hal G. Human papillomavirus vaccination acceptability among female university students in South Africa. Asian Pac J Cancer Prev 2013;14:4865-9.

78 Khoza N, Stadler J, MacPhail C, et al. Cash transfer interventions for sexual health: meanings and experiences of adolescent males and females in inner-city Johannesburg. BMC Public Health 2018;18:1-N.PAG.

79 Struthers A, Charette C, Bapuji SB, et al. The acceptability of emental health services for children, adolescents, and young adults: a systematic search and review. Can J Commun Ment Health 2015;34:1-21.

80 Behav NH. The importance of no evidence 2019;3:197

81 Mlinarić A, Horvat M, Šupak Smolčić V, Smolčić upak V. Dealing with the positive publication bias: why you should really publish your negative results. Biochem Med 2017;27:030201.

82 Archibald D, Patterson R, Haraldsdottir E, et al. Mapping the progress and impacts of public health approaches to palliative care: a scoping review protocol. BMJ Open 2016;6:e012058.

83 James KL, Randall NP, Haddaway NR. A methodology for systematic mapping in environmental sciences. Environmental Evidence 2016;5:7.

84 Grant MJ, Booth A. A typology of reviews: an analysis of 14 review types and associated methodologies. Health Info Libr J 2009;26:91-108.

85 Cordova D, Alers-Rojas F, Lua FM, et al. The usability and acceptability of an adolescent mHealth HIV/STI and drug abuse preventive intervention in primary care. Behav Med 2018;44:36-47.

86 Schleider JL, Dobias M, Sung J, et al. Acceptability and utility of an open-access, online Single-Session intervention platform for adolescent mental health. JMIR Ment Health 2020;7:e20513.

87 Belzer ME, Kolmodin MacDonell K, Clark LF, et al. Acceptability and feasibility of a cell phone support intervention for youth living with HIV with nonadherence to antiretroviral therapy. AIDS Patient Care STDS 2015;29:338-45.

88 Ranney ML, Choo EK, Cunningham RM, et al. Acceptability, language, and structure of text message-based behavioral interventions for high-risk adolescent females: a qualitative study. Journal of Adolescent Health 2014;55:33-40.

89 Callahan DG, Garabedian LF, Harney KF, et al. Will it hurt? the intrauterine device insertion experience and long-term acceptability among adolescents and young women. J Pediatr Adolesc Gynecol 2019;32:615-21.

90 Yankah E, Mohamed O, Wringe A, et al. Feasibility and acceptability of mobile phone platforms to deliver interventions to address gender-based violence among Syrian adolescent girls and young women in Izmir, Turkey. Vulnerable Child Youth Stud 2020;15:133-43.

91 World Health Organization. Who guideline: recommendations on digital interventions for health system strengthening: World Health organization 2019.

92 Unicef. Beyond masks: societal impacts of COVID-19 and accelerated solutions for children and adolescents 2020.

93 Boydell KM, Hodgins M, Pignatiello A. Using technology to deliver mental health services to children and youth: a scoping review. $J$ Can Acad Child Adolesc Psychiatry 2014;23:87-99.

94 Jolly S, Oosterhoff P, Faith B. A review of the evidence: sexuality education for young people in digital spaces 2020 .

95 Keeley B, Little C. The state of the worlds children 2017: children in a digital world: ERIC; 2017. 
96 Gunnlaugsson G, Whitehead TA, Baboudóttir Fatou N'dure, FNd $\mathrm{B}$, et al. Use of digital technology among adolescents attending schools in Bissau, Guinea-Bissau. Int J Environ Res Public Health 2020;17:8937.

97 Sam-Agudu NA, Folayan MO, Ezeanolue EE. Seeking wider access to HIV testing for adolescents in sub-Saharan Africa. Pediatr Res 2016;79:838-45.

98 Reif LK, Abrams EJ, Arpadi S, et al. Interventions to improve antiretroviral therapy adherence among adolescents and youth in low- and middle-income countries: a systematic review 2015-2019. AIDS Behav 2020;24:2797-810.

99 Cislaghi B, Shakya H, Norms S. And adolescents' sexual health: an introduction for practitioners working in low and Mid-income African countries. Afr J Reprod Health 2018;22:38-46.

100 Sanchez EK, Speizer IS, Tolley E, et al. Influences on seeking a contraceptive method among adolescent women in three cities in Nigeria. Reprod Health 2020;17:167.

101 Sisson $\mathrm{H}$, Wilkinson Y. An integrative review of the influences on decision-making of young people about human papillomavirus vaccine. J Sch Nurs 2019;35:39-50.

102 Karlsson LC, Soveri A, Lewandowsky S, et al. Fearing the disease or the vaccine: the case of COVID-19. Pers Individ Dif 2021;172:110590.

103 Sommers M. The outcast majority: war, development, and youth in Africa. University of Georgia Press, 2015.

104 United Nations. The sustainable development goals report 2019: United nations; 2019.

105 Smith JH, Whiteside A. The history of AIDS exceptionalism. J Int AIDS Soc 2010;13:47.
106 Sands P. Hiv: from exceptionalism to endgame. The Lancet 2018;392:261-2.

107 Laabes EP, Desai R, Zawedde SM, et al. How much longer will Africa have to depend on Western nations for support of its capacity-building efforts for biomedical research? Tropical Medicine International Health 2011;16:258-62.

108 Kasprowicz VO, Chopera D, Waddilove KD, et al. African-led health research and capacity building- is it working? BMC Public Health 2020;20.

109 Bautista T, James D, Amaro H. Acceptability of mindfulness-based interventions for substance use disorder: a systematic review. Complement Ther Clin Pract 2019;35:201-7.

110 Berry N, Lobban F, Emsley R, et al. Acceptability of interventions delivered online and through mobile phones for people who experience severe mental health problems: a systematic review. J Med Internet Res 2016;18:e121.

111 Mavhu W, Hatzold K, Madidi N, et al. Is the PrePex device an alternative for surgical male circumcision in adolescents ages 13-17 years? findings from routine service delivery during active surveillance in Zimbabwe. PLoS One 2019;14:e0213399.

112 Nuwasiima A, Nuwamanya E, Babigumira JU, et al. Acceptability and utilization of family planning benefits cards by youth in slums in Kampala, Uganda. Contracept Reprod Med 2019;4:10.

113 Cover J, Lim J, Namagembe A, et al. Acceptability of contraceptive self-injection with DMPA-SC among adolescents in Gulu district, Uganda. Int Perspect Sex Reprod Health 2017;43:153-62. 